\title{
Lignans from the bark of Eucommia ulmoides inhibited Ang II-stimulated extracellular matrix biosynthesis in mesangial cells
}

Zhen-yu Li $i^{1}$, Xiao-lan Deng ${ }^{2,3}$, Wei-hua Huang ${ }^{2}$, Ling Lii ${ }^{2,4}$, Hui Li ${ }^{2}$, Xian Jing ${ }^{2}$, Ying-ying Tian ${ }^{2}$, Pei-yu Lv' Tian-lun Yang ${ }^{1}$, Hong-hao Zhou ${ }^{2}$ and Dong-sheng Ouyang ${ }^{2^{*}}$

\begin{abstract}
Background: Tree bark of Eucommia ulmoides Oliv., (commonly well-known as "Du-zhong" in China), has been used to treat hypertension, hypercholesterolemia, hyperglycemia, hepatic fibrosis and renal injury. This study aims to investigate the effects of lignans extracted from the bark of Eucommia ulmoides Oliv. on Ang II-induced proliferation and extracellular matrix biosynthesis in rat mesangial cells.

Methods: Rat mesangial cells (RMCs) were cultured in vitro and divided into six groups (control, Ang II, losartan, and low, middle and high concentration lignans groups). RMC proliferation was measured by MTT assay. RT-qPCR and western blotting were used to detect mRNA and protein expression of collagen type I (Col I), collagen type III (Col III), collagen type IV (Col IV), fibronectin and aldose reductase (AR).

Results: Cellular proliferation induced by Ang II was significantly suppressed by Eucommia lignans of different concentrations $(P=0.034, P<0.001$, and $P<0.001)$. Treatment of cells with Ang II increased Col I, Col III, Col IV, and fibronectin mRNA expression, which was observed the protein level $(P<0.001, P<0.001, P=0.004$, and $P=0.004$, respectively). The increased mRNA expression and protein levels of Col I, Col III, Col IV, and fibronectin were diminished remarkably with by treatment Eucommia lignans, and elevated AR expression stimulated by Ang II was significantly inhibited by Eucommia lignans.
\end{abstract}

Conclusions: Eucommia lignans (Du-zhong) inhibited Ang Il-stimulated extracellular matrix biosynthesis in mesangial cells.

\section{Background}

Hypertension is the second leading cause of end-stage renal disease [1], resulting in hypertensive nephropathy, which usually starts with glomerulosclerosis [2,3]. The pathophysiologic process is associated with structural changes to renal glomeruli due to mesangial cell (MC) proliferation and abnormal accumulation of extracellular matrix (ECM) [3,4]. Angiotensin II (Ang II), the main effective peptide in the rennin-angiotensin system (RAS) is considered a key mediator in the development of hypertensive glomerulosclerosis [3,5]. RAS regulates the proliferation of MCs and increases the production of ECM, mainly

\footnotetext{
*Correspondence: ouyangyj@163.com

${ }^{2}$ Institute of Clinical Pharmacology, Hunan Key Laboratory of Pharmacogenetics, Central South University, 110 Xiang-Ya Street, Changsha, Hunan 410078, China

Full list of author information is available at the end of the article
}

through the induction of glomerular hypertension, as well as non-hemodynamic effects, which include the production of reactive oxygen species, up-regulation of profibrotic growth factors, such as platelet-derived growth factor (PDGF), transforming growth factor- $\beta 1$ (TGF- $\beta 1$ ), tumor necrosis factor- $\alpha$ (TNF- $\alpha$ ) and connective tissue growth factor, and macrophage activation and infiltration [3,6-8].

Aldose reductase (AR), a member of the aldo-keto reductase super family, catalyzes the conversion of glucose to sorbitol dependent on NADPH in the first step of the polyol pathway [9]. AR can be activated by TGF- $\beta 1$, oxidative stress and inflammation [9-12], to stimulate proliferation of MCs and deposition of ECM induced by TGF- $\beta 1$ and PDGF [13-16]. An over-expression of AR was observed in the renal tissue of spontaneous hypertensive rats (SHR) in our previous study [12]. AR might be 
involved in the pathological process induced by Ang II in MCs.

Cortex Eucommiae (Du-zhong), the dried bark of the Eucommia ulmoides Oliv. (Family: Eucommiaceae), has been served as a traditional tonic medicine and is thought to benefit the liver and kidney, strengthen tendons and bones, and prevent miscarriage [17]. The natural products that have been identified from Du-zhong include lignans, iridoids, flavonoids, polysaccharides, terpenes and protein [18], which possess various pharmacological effects, including antihypertensive, antioxidant, antimicrobial, and antiinflammatory properties $[9,18]$. We previously confirmed that lignans were the effective fraction of Du-zhong for antihypertension $[10,19]$. Further study showed that both $\mathrm{N}$-acetyl- $\beta$-D-glucosaminidase enzyme activity and the ratio of albumin to urinary creatinine decreased in spontaneous hypertensive rat (SHR)-treated with Eucommia lignans [12]. Eucommia lignans also inhibited the expression of collagen type III (Col III) in the glomerular basement membrane, and diminished the over-expression of AR in the kidney [11]. Accordingly, we hypothesized that lignans decreased the production of Col III by affecting AR expression and thus decreased damage to the glomerular structure [12].

This study aims to investigate the effects of lignans extracted from the bark of Eucommia ulmoides Oliv. On Ang II-induced proliferation and extracellular matrix biosynthesis in rat mesangial cells, and attempted to elucidate the mechanisms by which Eucommia lignans from $\mathrm{Du}$-zhong protecting against hypertensive renal injury in vitro.

\section{Methods}

\section{Materials and reagents}

RPMI-1640 medium, newborn calf serum (NCS), RTqPCR kits with Platinum ${ }^{\circ}$ SYBR $^{\circ}$ Green qPCR Super Mix-UDG, and primers for collagen I (Col I), Col III, collagen type IV (Col IV), fibronectin and AR were purchased from Invitrogen (Carlsbad, CA, USA). Antibodies for Col I, Col III, Col IV, fibronectin and AR for western blotting were supplied by Abcam (Cambridge, England) and Santa Cruz Biotechnology Inc. (CA, USA). The Cell Titer $96^{\circ}$ Aqueous One Solution Proliferation Assay for the 3-(4, 5-dimethylthiazol-2-yl)-2, 5-diphenyl tetrazolium bromide (MTT) method was provided by Promega (Madison, WI, USA). A Revert Aid First Strand cDNA Synthesis Kit was purchased from Thermo Scientific (Austin, TX, USA). Losartan was obtained commercially from the National Institute for Food and Drug Control (Beijing, China). Human Angiotensin II and other analytical grade reagents were purchased from Sigma-Aldrich (St. Louis, MO, USA).

Eucommia lignans were extracted at our own laboratory as described previously $[12,19,20]$. E. ulmoides were obtained from Changsha Medical Company (Hunan, China) in July 2009, and authenticated by Dr. Dong-Sheng Ouyang, one of the authors according to the methods described in the literature [21]. A voucher specimen of Eucommia ulmoides Oliv. (IBSC_0345347) was deposited at South China Botanical Garden Herbarium, Guangdong, China. Briefly, fresh Eucommia ulmoides Oliv. bark was cut into pieces and extracted with $60 \%$ ethanol purchased from Changsha Tianshun Chemical Co., Ltd (Hunan, China) at $70^{\circ} \mathrm{C}$ for $2 \mathrm{~h}$ (twice). The extract was subjected to macroporous resin supplied by Haiguang Chemical Industrial Company (Tianjin, China) and eluted with $80 \%$ ethanol after treatment with pure water as the eluent. The eluent was freeze-dried to powder and stored at $4{ }^{\circ} \mathrm{C}$. The lignans content in Eucommia lignans was $71 \%$, as determined by spectrophotometry on a Beckman Coulter DU 640 spectrophotometer (Beckman Coulter, Inc. USA) at $277 \mathrm{~nm}$, with pinoresinoldiglucoside used as the control which was supplied by college of chemistry and chemical engineering in Central South University (Hunan, China).

\section{Cell culture}

RMCs (HBZY-1 cells) were purchased from China Center for Type Culture Collection (Wuhan, China). After recovery, RMCs were cultured in RPMI-1640 medium supplemented with $10 \% \mathrm{NCS}$ at $37^{\circ} \mathrm{C}$ in a humidified atmosphere of $5 \% \mathrm{CO}_{2}$ in air.

\section{MTT assay}

RMCs were added into the wells of a 96-well plate at a density of 3000 cells per well and cultured in RPMI-1640 medium containing 10\% NCS. All incubations were performed in RPMI-1640 containing 1\% NCS when they grew to $60 \%$ confluence. The study included two parts: (1) Control group, Eucommia lignans groups (10, 20, 30, 40, 50, 60, 70, 80, or $90 \mathrm{mg} / \mathrm{L}$ Eucommia lignans); and (2) Control group, Ang II group (10 nM Ang II), Losartan group (10 nM Ang II with $20 \mu \mathrm{M}$ Losartan), Eucommia lignans groups (10 nM Ang II with 20, 40 and $80 \mathrm{mg} / \mathrm{L}$ Eucommia lignans). After $48 \mathrm{~h}$, the viability of RMCs was measuredby MTT method. Then, $20 \mu \mathrm{L}$ cell Titer $96^{\circ}$ Aqueous One Solution Reagent was added to the medium in each well, and the absorbance of solubilized blue formazan was recorded by a microplate reader (Molecular Devices, Spectra MAX. 250, USA) at $490 \mathrm{~nm}$ after $1 \mathrm{~h}$ at $37^{\circ} \mathrm{C}$ in a humidified $5 \% \mathrm{CO}_{2}$ atmosphere.

\section{Reverse transcription real-time quantitative PCR (RT-qPCR) assay}

RMCs were assigned to six groups: Control group, Ang II group (10 nM Ang II), Losartan group (10 nM Ang II with $20 \mu \mathrm{M}$ Losartan), and Eucommia lignans groups (10 nM Ang II with 20, 40 or 80 mg/L Eucommia lignans), 
in a 6-well plate, and cultured in RPMI-1640 medium containing 10\% NCS for $48 \mathrm{~h}$. Total RNA from RMCs was extracted by Trizol $^{\circledR}$ reagent (Invitrogen, Carlsbad, CA, USA) and the concentration was determined by spectrophotometry at 260 and $280 \mathrm{~nm}$. A reverted aid cDNA synthesis kit was used to perform the synthesis of first strand cDNA from total RNA templates. Real-time qPCR was performed by Platinum ${ }^{\bullet} \mathrm{SYBR}^{\bullet}$ Green qPCR Super Mix-UDG following the manufacturer's instructions. The gene-specific primers are listed in Table 1. The data were quantitatively analyzed by Stratagene Mx3000p Real-time PCR (Santa Clara, CA, USA). The glyceraldehyde phosphate dehydrogenase (GAPDH) gene was used as the internal control.

\section{Western blotting}

Total protein was extracted from RMCs with radio immunoprecipitation assay lysis buffer consisting of $10 \mathrm{mM}$ sodium phosphate (pH 7-8), $150 \mathrm{mM} \mathrm{NaCl}, 0.1 \%$ SDS, 0.5\% sodium deoxycholate and 1\% Triton X 100 after a 48-h culture under the conditions described above, and the protein concentration was determined using a bicinchoninic acid assay kit (Sigma-Aldrich, USA). A total of $40 \mu \mathrm{g}$ of total protein was separated on a $10 \%$ sodium dodecyl sulfate polyacrylamide gel (Invitrogen, Carlsbad, CA, USA) and transferred onto a polyvinylidenefluoride membrane (Millipore, USA). The membrane was blocked with 5\% skim milk solution in $0.1 \%$ tris-buffered saline Tween-20 (TBST) (Shanghai Bioscience Co. Ltd, China) over night. Subsequently, one of the primary antibodies (rabbit polyclonal for Col I, mouse monoclonal [FH-7A] for Col III, rabbit polyclonal for Col IV, mouse monoclonal [IST-9] for fibronectin, goat polyclonal for $\mathrm{AR}$, and rabbit polyclonal for GAPDH) was added for hybridization before being incubated with the specific secondary antibody after washing membranes with TBST (Shanghai Bioscience Co. Ltd, China) three times. Protein bands were determined

Table 1 Information on the primers used for real-time PCR

\begin{tabular}{lll}
\hline Gene & Primers & Product size (bp) \\
\hline AR & F: TCCCAGGATCAAGGAAATTG & 202 \\
& R: ACAACAGGAACTGGAGGGTG & \\
FN & F: AACGGCCCTGGTTGTACC & 285 \\
& R: CTCCAACATATAGCCACCAGTC & \\
Col I & F: GAGAGAGCATGACCGATGGA & 251 \\
& R: CGTGCTGTAGGTGAATCGAC & \\
Col III & F: GGCTGCACTAAACACACTGG & 229 \\
& R: TGGTGACGAGATAAAGCAAG & \\
Col IV & F: TGTCAGCAATTAGGCAGGTC & 205 \\
& R: CACCATGTTCGGAATGGTT \\
GAPDH & F: CAAGTTCAACGGCACAGTCAAG & 123 \\
& R: ACATACTCAGCACCAGCATCAC \\
\hline
\end{tabular}

by the enhanced chemiluminescence western blotting detection system. GAPDH was used as an internal standard for data normalization.

\section{Statistical analysis}

Data were shown as mean \pm standard deviation (SD) and were analyzed with SPSS 17.0 software (SPSS Inc., USA). A $P$ value less than 0.05 was considered statistically significant. Significant differences between multiple groups were analyzed by one-way analysis of variance (ANOVA) followed by a Dunnett's post-hoc test.

\section{Results}

\section{Effects of Eucommia lignans on RMC growth}

In comparison with the control, there was no significant change in the number of cells treated with Eucommia lignans in the 10, 20, 30, 40, 50, 60, 70 and $80 \mathrm{mg} / \mathrm{L}$ groups $(P=0.983,0.986,1.000,0.900,0.920,0.515,0.515$, and 0.249 , respectively). However, cellular viability decreased markedly in the group incubated with $90 \mathrm{mg} / \mathrm{L}$ Eucommia lignans $(P=0.001)$ (Figure 1$)$. Therefore, the incubated concentrations of Eucommia lignans for the following experiments were 20, 40 and $80 \mathrm{mg} / \mathrm{L}$.

\section{Inhibition of Eucommia lignans on Ang II-induced RMC proliferation}

The Ang II receptor blocker, losartan $(20 \mu \mathrm{M})$, significantly decreased the proliferation of RMCs induced by Ang II $(P=0.004)$. The inhibitory effects were also observed in the different Eucommia lignans-treated groups $(P=0.034, P<0.001$, and $P<0.001)$ (Figure 2$)$.

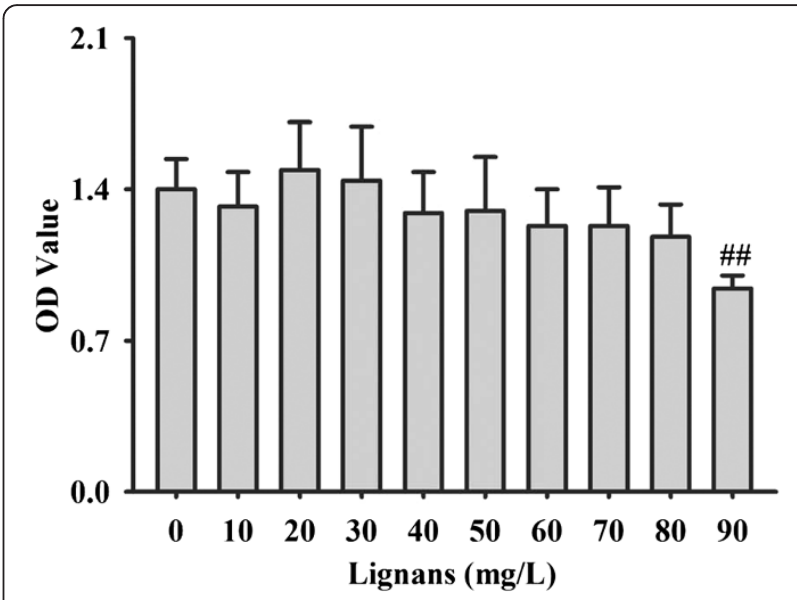

Figure 1 Effects of Eucommia lignans on RMCs growth. RMCS were treated with various concentrations of Eucommia lignans (10, $20,30,40,50,60,70,80$, or $90 \mathrm{mg} / \mathrm{L}$ ) for $48 \mathrm{~h}$, and cell viability was assessed by MTT method. Results were given in mean $\pm S D(n=6)$. ${ }^{\# \#} P<0.01$ vs. the control group. 


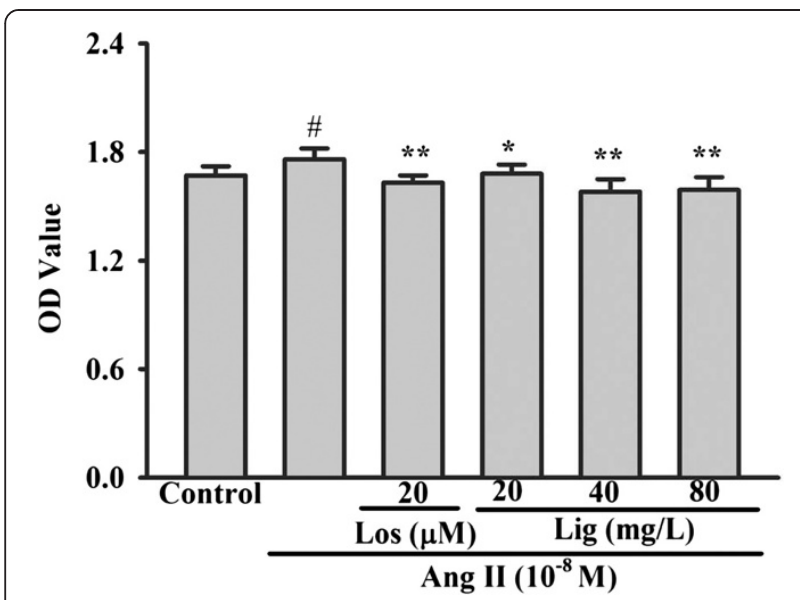

Figure 2 Inhibitory effects of Eucommia lignans on Ang II-induced RMCs proliferation. All values represented mean $\pm S D(n=6)$. Los: losartan; Lig: lignans. ${ }^{\#} P<0.05$ vs. the control group, ${ }^{*} P<0.05,{ }^{* * *} P<0.01$ vs. Ang II group.

Reduction of Eucommia lignans on Ang II-induced ECM biosynthesis in RMCs

The changes in Col I, Col III, Col IV and fibronectin production are shown in Figure 3. mRNA and protein expression increased with Ang II stimulation. All of the increased expression levels induced by Ang II could be attenuated by losartan treatment (Col IV mRNA, $P=$ 0.007; others, $P<0.001)$. Furthermore, Eucommia lignans also significantly diminished their ascended expression (Col I protein of $20 \mathrm{mg} / \mathrm{L}, P=0.001$; Col I protein of $40 \mathrm{mg} / \mathrm{L}, P=0.002$; Col IV mRNA of $80 \mathrm{mg} / \mathrm{L}, P=0.031$; others, $P<0.001$ ), although decreases of the Col IV mRNA level of the low and middle concentration lignans groups did not reach a statistically significant difference $(P=0.084$ and $P=0.134$ ). Eucommia lignans could suppress Ang IIstimulated biosynthesis of ECM in RMCs (Figure 3B).

\section{Block of Eucommia lignans on Ang II-induced AR expression in RMCs}

The mechanisms of Eucommia lignans inhibitory effects were tentatively elucidated from data of our previous animal experiments [22]. Both mRNA and protein expression of AR were effectively enhanced by Ang II $(P<$ 0.001) (Figure 4). Losartan and Eucommia lignans clearly attenuated all expression stimulated by Ang II (Losartan, $P=0.045 ; 20 \mathrm{mg} / \mathrm{L}$ Lignans, $P=0.01$; others, $P<0.001$ ). The experiment demonstrated that Eucommia lignans could suppress Ang II-induced AR expression in RMCs.

\section{Discussion}

Eucommia lignans (10 to $90 \mathrm{mg} / \mathrm{L}$ ) was incubated with RMCs, according to our previous study with renal tubular epithelial cells (HK-2 cells) [12]. Eucommia lignans at $90 \mathrm{mg} / \mathrm{L}$ affected the normal growth of RMCs. Therefore,

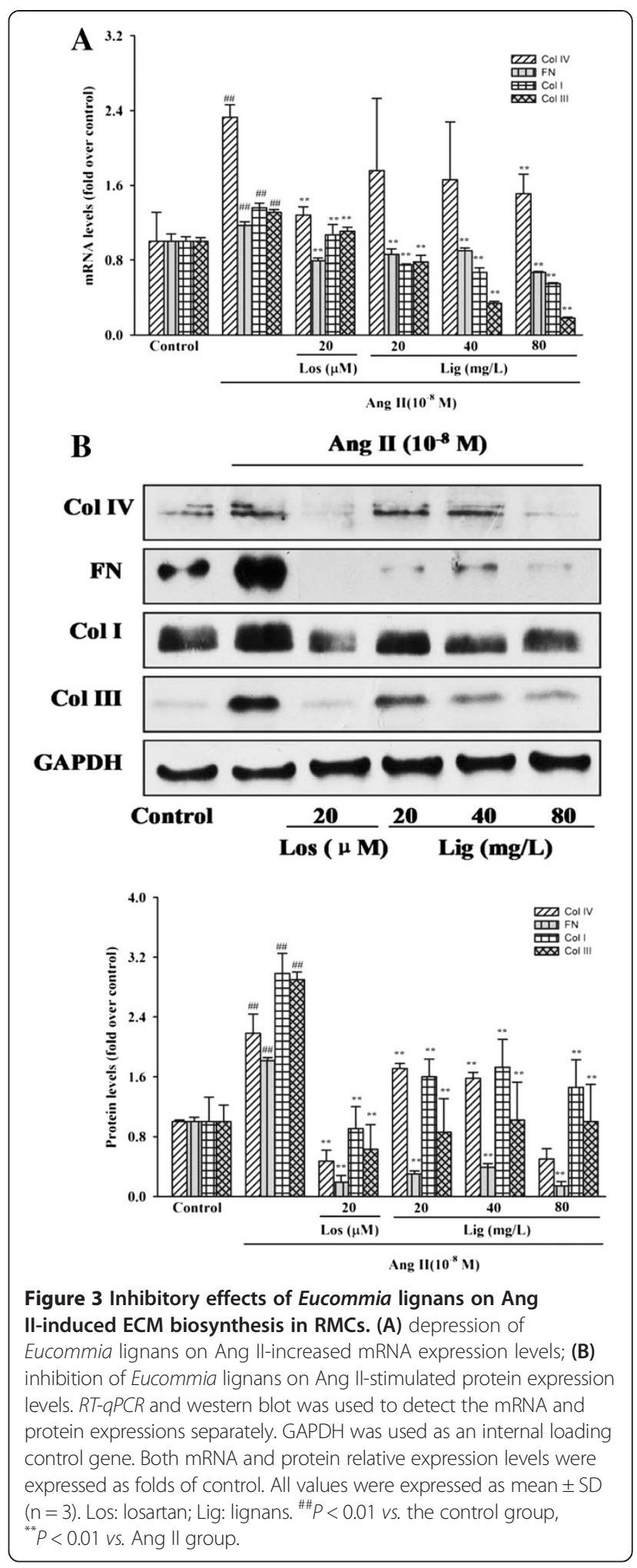

Eucommia lignans amounts in the subsequent experiments were set as 20,40 and $80 \mathrm{mg} / \mathrm{L}$.

The result consistent with those previous reports on the pathogenesis of hypertensive glomerulosclerosis [3,5], and 


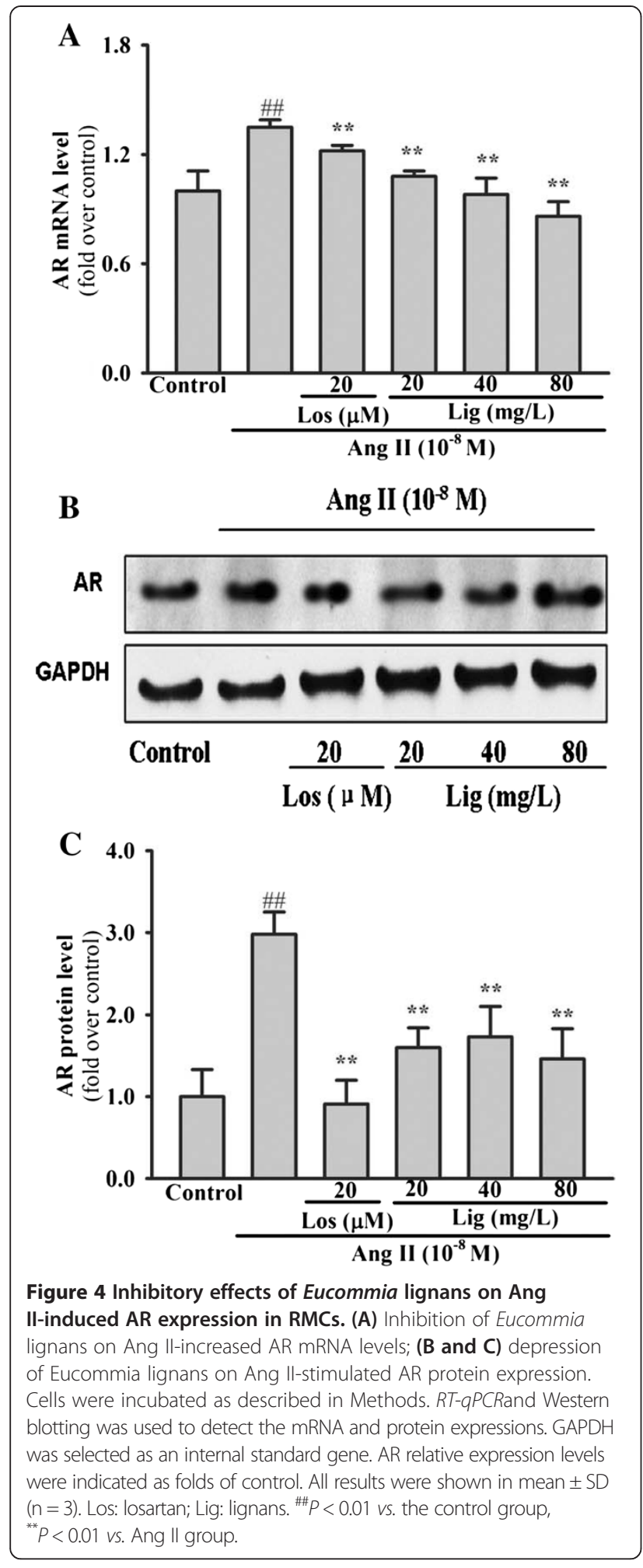

stimulates MC proliferation and biosynthesis of ECM including mainly Col IV, fibronectin, Col I and Col III in in vivo or in vitro [4,23-28]. Our present study found that Ang II (10 nM) stimulated proliferation and production of Col IV, fibronectin and Col I in RMCs, and that both
mRNA and protein of Col III were over-expressed in RMCs induced by Ang II.

In the current study, Ang II-induced RMC proliferation was significantly inhibited by Eucommia lignans, and there was a reduction in the raised expression of Col I, Col III, Col IV and fibronectin at both mRNA and protein levels. However, the mechanisms of Eucommia lignans in preventing Ang II-induced proliferation of RMC and production of ECM are poorly defined. According to some reports, AR, as a member of the aldo-ketoreductase superfamily, is involved in the cellular proliferation and ECM (Col I, Col IV and fibronectin) production induced by TGF- $\beta 1$ or PDGF in human or rat MCs, and TGF- $\beta 1$ and PDGF are downstream genes of Ang II [13-16]. Therefore, we tested the hypothesis that AR might participate in the pathological process in RMCs induced by Ang-II. This study demonstrated both AR mRNA and protein levels increase in RMCs were induced by Ang-II, in addition to our previous finding that Eucommia lignans decreased the production of Col III by degrading the expression of AR protein in SHR renal tissue [12], showed that the Eucommia lignans' effects on Ang II-induced pathological changes in RMCs involved the reduction in the expression of AR. Our further studies will examine the signal pathways for the reduction of Eucommia lignans by AR expression.

\section{Conclusions}

Eucommia lignans (Du-zhong) inhibited Ang II-stimulated extracellular matrix biosynthesis in mesangial cells.

\section{Abbreviations}

Ang II: Angiotensin II; AR: Aldose reductase; Col I: Collagen type I; Col III: Collagen type III; Col IV: Collagen type IV; ECM: Extracellular matrix; GAPDH: Glyceraldehyde phosphate dehydrogenase; MCs: Mesangial cells; MTT: 3-(4, 5-dimethylthiazol-2-yl)-2, 5-diphenyl tetrazolium bromide; NCS: Newborn calf serum; PDGF: Platelet-derived growth factor; RAS: Rennin-angiotensin system; SHR: Spontaneous hypertensive rat; TGF- $\beta 1$ : Transforming growth factor- $\beta 1$; TNF-a: tumor necrosis factor- $\alpha$.

\section{Competing interests}

The authors declare that they have no competing interests.

\section{Authors' contributions}

$D O$ and $H Z$ designed this study. $Z L, X D, L L, H L, X J, Y T$, and $P L$ performed the experiments. $Z \mathrm{~L}, \mathrm{XD}$ and $\mathrm{WH}$ wrote the manuscript. All authors have read and approved the final manuscript.

\section{Acknowledgments}

This study was supported by the National Sci-Tech Support Plan of China (SQ2010BAJY1411-08), National Development of Key Novel Drugs for Special Projects of China (2012ZX09303014001), the Hunan Provincial Natural Science Foundation of China (12JJ7006), the Innovation Project for 2011 Graduates of Central-South University (2010ssxt272), and the Fundamental Research Funds for the Central Universities of Central South University (1681-7608040003).

\section{Author details}

${ }^{1}$ The Xiangya Hospital Central-South University, Changsha, Hunan 410078, China. ${ }^{2}$ Institute of Clinical Pharmacology, Hunan Key Laboratory of Pharmacogenetics, Central South University, 110 Xiang-Ya Street, Changsha, Hunan 410078, China. ${ }^{3}$ Haikou Hospital Affiliated to Xiangya Central-South University, Haikou, Hainan 570208, China. ${ }^{4}$ Institute of Hepatobiliary Diseases 
of Wuhan University, Zhongnan Hospital of Wuhan University, Wuhan, Hubei 430071, China.

Received: 31 July 2013 Accepted: 11 February 2014

Published: 14 February 2014

\section{References}

1. 2009 Annual data report: atlas of end-stage renal disease in the United States. [http://www.usrds.org/2009/slides/indiv/INDEX_CKD.HTML]

2. Lee SB, Kalluri R: Mechanistic connection between inflammation and fibrosis. Kidney Int Suppl 2010, 119:S22-S26.

3. Kagami S: Involvement of glomerular renin-angiotensin system (RAS) activation in the development and progression of glomerular injury. Clin Exp Nephrol 2012, 16:214-220.

4. Ding G, Zhang A, Huang S, Pan X, Zhen G, Chen R, Yang T: ANG II induces c-Jun $\mathrm{NH}$ 2-terminal kinase activation and proliferation of human mesangial cells via redox-sensitive transactivation of the EGFR. Am J Physiol Renal Physiol 2007, 293:F1889-F1897.

5. Rüster C, Wolf G: Angiotensin II as a morphogenic cytokine stimulating renal fibrogenesis. J Am Soc Nephrol 2011, 22:1189-1199.

6. Brenner BM: Remission of renal disease: recounting the challenge, acquiring the goal. J Clin Invest 2002, 110:1753-1758.

7. Chen XM, Qi W, Pollock CA: CTGF and chronic kidney fibrosis. Front BiosCi (Schol Ed) 2009, 1:132-141.

8. Lan HY: Diverse roles of TGF-beta/Smads in renal fibrosis and inflammation. Int J Biol Sci 2011, 7:1056-1067.

9. Gu J, Yan J, Wu W, Huang Q, Ouyang DS: Research progress in aldose reductase. Zhong Nan Da Xue Xue Bao Yi Xue Ban 2010, 35:395-400.

10. Wang JL, Liu EW, Zhang Y, Wang T, Han LF, Gao XM: Validation of a HPLCtandem MS/MS method for pharmacokinetics study of (+)-pinoresinoldi-beta-D-glucopyranoside from Eucommia ulmoides Oliv extract in rats' plasma. J Ethnopharmacol 2012, 139:337-342.

11. Gu J, Wang JJ, Yan J, Cui CF, Wu WH, Li L, Wang ZS, Yu M, Gao N, Liu L, Ouyang DS: Effects of lignans extracted from Eucommia ulmoides and aldose reductase inhibitor epalrestat on hypertensive vascular remodeling. J Ethnopharmacol 2011, 133:6-13.

12. Li L, Yan J, Hu K, Gu J, Wang JJ, Deng XL, Li H, Jing X, Li ZY, Ye QF, Ouyang DS: Protective effects of Eucommia lignans against hypertensive renal injury by inhibiting expression of aldose reductase. J Ethnopharmacol 2012, 139:454-461.

13. Jiang $T$, Che $Q$, Lin $Y$, Li H, Zhang $N$ : Aldose reductase regulates TGF-beta1-induced production of fibronectin and type IV collagen in cultured rat mesangial cells. Nephrology (Carlton) 2006, 11:105-112.

14. Huang $P$, Zhang $Y$, Jiang $T$, Zeng $W$, Zhang $N$ : Aldose reductase is a potent regulator of TGF-beta1 induced expression of fibronectin in human mesangial cells. Mol Biol Rep 2010, 37:3097-3103.

15. Zou L, Wang W, Xu Z, Zhang N, Jiang T: Aldose reductase regulates platelet-derived growth factor-induced proliferation through mediating cell cycle progression in rat mesangial cells. Int J Mol Med 2012, 30:409-416.

16. Zhang $Y$, Huang $P$, Jiang $T$, Zhao J, Zhang $N$ : Role of aldose reductase in TGF-beta1-induced fibronectin synthesis in human mesangial cells. Mol Biol Rep 2010, 37:2735-2742.

17. National PCoC: Chinese Pharmacopoeia. 2010th edition. Beijing: China Medical Science and Technology Press; 2010

18. Liu E, Han L, Wang J, He W, Shang H, Gao X, Wang T: Eucommia ulmoides bark protects against renal injury in cadmium-challenged rats. J Med Food 2012, 15:307-314

19. Luo LF, Wu WH, Zhou YJ, Yan J, Yang GP, Ouyang DS: Antihypertensive effect of Eucommia ulmoides Oliv. extracts in spontaneously hypertensive rats. J Ethnopharmacol 2010, 129:238-243.

20. Liu N, Chen XQ, Du H, Xue XJ, Ouyang DS: Separation and purification of the lignans from Eucommia ulmoides. HuaXue Tong Bao 2006, 69:4

21. Zhang Q: Sequence analysis of chloroplast maturase $K$ gene of Chinese medical plant Eucommia ulmoides. ShengTai KeXue 2004, 23:141-143.

22. Li ZY, Gu J, Yan J, Wang JJ, Huang WH, Tan ZR, Zhou G, Chen Y, Zhou HH, Ouyang DS: Hypertensive cardiac remodeling effects of lignan extracts from Eucommia ulmoidesoliv. bark - a famous traditional Chinese medicine. Am J Chin Med 2013, 41:801-815.

23. Wolf G, Haberstroh U, Neilson EG: Angiotensin II stimulates the proliferation and biosynthesis of type I collagen in cultured murine mesangial cells. Am J Pathol 1992, 140:95-107.
24. Block K, Ricono JM, Lee DY, Bhandari B, Choudhury GG, Abboud HE, Gorin Y: Arachidonic acid-dependent activation of a p22(phox)-based NAD(P)H oxidase mediates angiotensin II-induced mesangial cell protein synthesis and fibronectin expression via Akt/PKB. Antioxid Redox Signal 2006, 8:1497-1508.

25. Huang $Y$, Wongamorntham S, Kasting J, McQuillan D, Owens RT, Yu L, Noble NA, Border W: Renin increases mesangial cell transforming growth factor-beta1 and matrix proteins through receptor-mediated, angiotensin II-independent mechanisms. Kidney Int 2006, 69:105-113.

26. Zhang J, Noble NA, Border WA, Huang Y: Infusion of angiotensin-(1-7) reduces glomerulosclerosis through counteracting angiotensin II in experimental glomerulonephritis. Am J Physiol Renal Physiol 2010, 298:F579-F588.

27. Davis LK, Rodgers BD, Kelley KM: Angiotensin II- and glucose-stimulated extracellular matrix production: mediation by the insulin-like growth factor (IGF) axis in a murine mesangial cell line. Endocrine 2008, 33:32-39.

28. Banes-Berceli AK, Shaw S, Ma G, Brands M, Eaton DC, Stern DM, Fulton D, Caldwell RW, Marrero MB: Effect of simvastatin on high glucose- and angiotensin II-induced activation of the JAK/STAT pathway in mesangial cells. Am J Physiol Renal Physiol 2006, 291:F116-F121.

doi:10.1186/1749-8546-9-8

Cite this article as: Li et al.: Lignans from the bark of Eucommia ulmoides inhibited Ang II-stimulated extracellular matrix biosynthesis in mesangial cells. Chinese Medicine 2014 9:8.

\section{Submit your next manuscript to BioMed Central and take full advantage of:}

- Convenient online submission

- Thorough peer review

- No space constraints or color figure charges

- Immediate publication on acceptance

- Inclusion in PubMed, CAS, Scopus and Google Scholar

- Research which is freely available for redistribution

Submit your manuscript at www.biomedcentral.com/submit
C) Biomed Central 